IZA DP No. 7183

Social Distance and Trust:

Experimental Evidence from a Slum in Cairo

Christine Binzel

Dietmar Fehr

January 2013 


\title{
Social Distance and Trust: Experimental Evidence from a Slum in Cairo
}

\author{
Christine Binzel \\ Heidelberg University \\ and IZA
}

\section{Dietmar Fehr}

Wissenschaftszentrum Berlin (WZB)

\author{
Discussion Paper No. 7183 \\ January 2013
}

\author{
IZA \\ P.O. Box 7240 \\ 53072 Bonn \\ Germany \\ Phone: +49-228-3894-0 \\ Fax: +49-228-3894-180 \\ E-mail: iza@iza.org
}

Any opinions expressed here are those of the author(s) and not those of IZA. Research published in this series may include views on policy, but the institute itself takes no institutional policy positions. The IZA research network is committed to the IZA Guiding Principles of Research Integrity.

The Institute for the Study of Labor (IZA) in Bonn is a local and virtual international research center and a place of communication between science, politics and business. IZA is an independent nonprofit organization supported by Deutsche Post Foundation. The center is associated with the University of Bonn and offers a stimulating research environment through its international network, workshops and conferences, data service, project support, research visits and doctoral program. IZA engages in (i) original and internationally competitive research in all fields of labor economics, (ii) development of policy concepts, and (iii) dissemination of research results and concepts to the interested public.

IZA Discussion Papers often represent preliminary work and are circulated to encourage discussion. Citation of such a paper should account for its provisional character. A revised version may be available directly from the author. 


\section{ABSTRACT \\ Social Distance and Trust: Experimental Evidence from a Slum in Cairo*}

While strong social ties help individuals cope with missing institutions, trade is essentially limited to those who are part of the social network. We examine what makes the decision to trust a stranger different from the decision to trust a member of a given social network (a friend), by comparing the determinants of these two decisions for the same individual. We implement a binary trust game with hidden action in a lab-in-the-field experiment with residents of an informal housing area in Cairo. Our results show that trust is higher among friends than among strangers and that higher trust among friends is related to the principal's belief of trustworthiness. However, on average a principal underestimates her friend's trustworthiness leading to inefficient outcomes. Our findings suggest that even within a social network, trade may often be limited to exchanges with few information asymmetries.

JEL Classification: C72, C93, D82, O12

Keywords: $\quad$ trust, social distance, hidden action, solidarity, economic development

Corresponding author:

Christine Binzel

Department of Economics

Heidelberg University

Bergheimer Str. 58

69115 Heidelberg

Germany

E-mail: christine.binzel@awi.uni-heidelberg.de

\footnotetext{
* The paper has greatly benefited from comments from the editor, Dean Karlan, and an anonymous referee, as well as Iris Bohnet, Tilman Brück, Julian Jamison, Stefan Klonner, Alexander Koch, Dorothea Kübler, Jeffrey Nugent, Jörg Oechssler, Imran Rasul, Arno Riedl, Jennifer Rontganger, Bruce Sacerdote, and Laura Schechter. We also thank seminar participants at DIW Berlin, Frankfurt University, Humboldt University of Berlin, Yale University and at the ESA European Meeting 2008, Econometric Society Summer Meeting 2009, VfS Annual Meeting 2009, ERF Annual Conference 2009, the EEA Congress 2010, and the AEA Meeting 2011. We are indebted to the Participatory Development Program in Urban Areas of the German Agency for International Cooperation (GIZ) in Cairo, in particular to its staff at the local office in Manshiet Nasser and to our research assistants from Cairo University. Financial support from DIW Berlin, the Economic Research Forum (ERF) and the German Research Foundation (DFG) through SFB 649 "Economic Risk" is gratefully acknowledged.
} 


\section{Introduction}

In developing countries formal institutions are often weak or non-existent. As a means of coping with such an insecure environment, individuals often establish strong social ties with other members of their immediate community and beyond. Social networks increase people's access to goods and services through reciprocal exchange (Kranton, 1996), mutual insurance (Fafchamps, 1992; Foster and Rosenzweig, 2001) and informal contract enforcement as exercised, for instance, in rotating savings and credit associations and in group banking (Karlan, 2007; Cox and Fafchamps, 2008; Karlan et al., 2009). However, one important inefficiency exhibited by social networks is that trade is essentially limited to members of a given network (Munshi, 2006). For individuals to overcome this limitation and to enter market exchanges, trust in strangers plays an important role. More generally, trust can help achieve efficient outcomes in economic exchanges when information asymmetries are present (Karlan, 2005; Karlan et al., 2009).

We examine the determinants of trust in an environment in which social networks play a crucial role. We are interested in both trust in strangers and trust within a given social network and ask what makes an individual's decision to trust a stranger different from her decision to trust a member of her own social network (henceforth, a "friend"). This question is important as data from surveys and from trust games suggest that trust in strangers - generalized trust - is low in developing countries, which is seen by many as an impediment to economic growth and development (e.g., Knack and Keefer, 1997; Sobel, 2002; Cardenas and Carpenter, 2008; Bohnet, Herrmann and Zeckhauser, 2010).

To study this question, we implemented a binary trust game in a lab-in-the-field experiment with residents of Manshiet Nasser, an informal housing area in Cairo. ${ }^{1}$ Our experimental design allows us to analyze the effect of a change in social distance between the trustor (principal) and trustee (agent) on trust behavior in a within-subject design. Variation in social distance was created by requiring residents to participate in the experiment together with a friend and to play the trust game both with their friend and with a randomly chosen, ex-ante unknown participant (i.e., a "stranger"). ${ }^{2}$ In order to ensure that the reduction in social distance between players does not

\footnotetext{
${ }^{1}$ Trust is defined as placing something valuable at the disposal of another person, the trustee, without being able to ensure that she will not misuse it. Trust thus creates a situation where the trustor is vulnerable to the trustee (Coleman, 1990). In the binary trust game, placing trust pays off if the trustee is trustworthy, but not if the trustee is untrustworthy.

${ }^{2}$ In the theoretical literature, social distance is usually defined as the path length between trading partners in social networks (e.g., Jackson, 2008). According to this definition, direct friends are connected by the shortest possible path in a network, whereas the path length to strangers is infinite.
} 
affect trust through increased availability of informal enforcement mechanisms, we use a binary trust game design in which the agent can hide her behavior (for details see section 2.1). We focus on two factors that have been shown to affect trust in strangers and that are likely to vary with social distance: expectations of trustworthiness and other-regarding preferences. That is, we are particularly interested in whether higher trust in friends results from stronger solidarity - as measured by dictator games in which the social distance between players is varied - or whether beliefs play a greater role. ${ }^{3}$

Our results show that, as expected, trust is higher among socially close persons than among strangers. Based on our binary belief measure, this can be explained by the fact that on average a principal is more likely to trust when she expects her friend to be trustworthy while this is not the case when the agent is a stranger. Principals thus appear to be more confident about their stated belief when interacting with a socially close person. Surprisingly, however, principals' expectations about agents' trustworthiness are not more accurate in the friend than in the stranger pairing. In particular, a principal underestimates on average the trustworthiness of her friend, leading to a substantial fraction of inefficient outcomes. We try to explain this finding by contrasting the determinants of principals' expectations about agents' trustworthiness with the determinants of agents' actual trustworthiness. While solidarity is a main determinant of an agent's trustworthiness, it does not on average correlate with a principal's expectation. This may suggest that in environments with strong norms of solidarity, agents' ability to successfully communicate their trustworthiness within their social network is limited.

Other recent studies have made use of individuals' real-world social networks in experiments both in developed and in developing countries, including Leider et al. (2009), D'Exelle and Riedl (2010), Goeree et al. (2010), Brañas-Garza et al. (2010), and Ligon and Schechter (2012). All five of these studies, however, were interested in how social distance between players affects prosocial giving in dictator games. ${ }^{4}$ Amongst others, they find that a decrease in social distance leads to an increase in the amount given by the dictator. The approach taken in this study resembles the trust experiment conducted by Glaeser et al. (2000), who allowed college students to self-select into

\footnotetext{
${ }^{3}$ Previous experimental studies on trust (in strangers) in developing countries have mostly used a continuous trust game ("investment game") based on Berg, Dickhaut and McCabe (1995) and have, for instance, related trust behavior to individual characteristics - such as age, gender, and risk preferences - and to beliefs (e.g., Barr, 2003; Schechter, 2007), as well as to real-world behavior (Karlan, 2005).

${ }^{4}$ In previous experimental studies, the term "social distance" has mainly been used to describe changes in the degree of anonymity either between participants and the experimenter, for instance, by using double-blind procedures (e.g., Hoffman, McCabe and Smith, 1996), or between participants, for instance, by providing certain information about the opponent (e.g., gender or last name) or by letting participants meet before taking the decision (e.g., Bohnet and Frey, 1999).
} 
pairs upon arrival at the lab, thereby raising the likelihood that students knew each other. They find significantly higher levels of trust and trustworthiness for pairs that are closer socially, which may, however, in part be due to the observability of choices and, hence, the possibility of informal enforcement. Our design, in contrast, rules out this possibility and, by using a within-subject design, we are able to examine what drives changes in trust in response to an increase or a decrease in the social distance between players.

The rest of this paper is organized as follows: in Section 2, we give an overview of the experimental procedures along with a description of the game setups and empirical strategy. Section 3 discusses the main results, while Section 4 examines the determinants of principals' expectations in the trust game. Section 5 concludes.

\section{Research Design}

In the following, we provide a short description of the background and the procedures of our study as well as the game designs (more detailed information can be found in the Web Appendix). The study was conducted in May 2008 in Manshiet Nasser, one of the largest and oldest informal housing areas in Cairo. Similar to other informal housing areas, Manshiet Nasser is characterized by a high population density and a lack of basic infrastructure in many of its neighborhoods.

Three female recruiters were assigned to different districts in order to recruit participants. Recruited participants (invitees) were told that participation in the experiment was only possible together with a friend, excluding direct family members and minors. In total, 144 slum dwellers from the various districts of Manshiet Nasser participated in a total of five experimental sessions. The participants exhibited substantial heterogeneity with respect to their socio-economic status (see Appendix Table 4). ${ }^{5}$ Educational attainment ranged from illiterates (30\% of our sample) to university graduates (10\%). About $40 \%$ of the participants received a regular wage, with an average monthly income of 377 Egyptian pounds (L.E.), equivalent to about 71 US $\$$ at the time of the experiment. ${ }^{6}$ In contrast, friend pairs exhibited very similar characteristics with regard to age, schooling, employment status, and wealth. All our friend pairs were same-sex pairs, which likely reflects the strong gender norms in Egypt. About $60 \%$ of friend pairs saw each other on a daily basis and most had known each other for more than five years.

\footnotetext{
${ }^{5}$ Note that we do not draw on a representative sample since we are mainly interested in a relative comparison of trust. Representative samples have recently been used in order to compare absolute levels of trust across populations (e.g., Cardenas et al., 2009).

${ }^{6}$ The exchange rate was about 1 US\$ to 5.3 Egyptian pounds (L.E.).
} 
The experimental sessions were run by a female instructor, who was supported by a large group of assistants, both male and female. The instructions were read aloud and the games and procedures were demonstrated in front of the participants. Participants made their decisions in private and, if necessary, an assistant answered questions and explained the tasks individually. Each session started with the trust game followed by two dictator games, a summing-up and an interview-based questionnaire, which contained questions on socio-economic characteristics, on other-regarding and risk preferences and on characteristics of their relationship to their friend. The trust game was always played first, because it involved the most effort to explain and we wanted the participants' concentrated attention. Participants received the instructions for each game separately and there was no feedback about outcomes between the games. On average, participants earned a total of 34 L.E. (about 6.4 US\$), which was more than twice a worker's daily wage.

\subsection{Trust Game}

We used a binary trust game with hidden action similar to that conducted by Charness and Dufwenberg (2006). The trust game works as follows (see Figure 1): the principal can choose Distrust or Trust. $^{7}$ In the former case, both the principal and the agent receive a payoff of 10 L.E. In the latter case, the agent has the choice between Betray, yielding a payoff of 27 L.E., and Trustworthy, yielding a payoff of 20 L.E. If the agent chooses Betray, the principal receives a payoff of 4 L.E. If instead the agent chooses Trustworthy, the principal's trust is rewarded with a probability of $p=5 / 6$, yielding a payoff of 24 L.E. In $p=1 / 6$ cases, however, the principal receives a payoff of 4 L.E. only. Due to this random factor, if the principal receives a payoff of 4 L.E., she is unable to conclude with certainty whether or not the agent chose Betray. The possibility of agents to hide their action ensures that even when the principal and the agent know each other personally, the principal cannot retaliate against the agent in the case of a low payoff.

Applying backward induction and assuming selfish and risk-neutral participants, a principal will choose Distrust, since the agent will maximize her payoff by choosing Betray. Note that this unique equilibrium (Distrust, Betray) is inefficient and that choosing Trust will always lead to a higher sum of payoffs. In fact, if the principal chooses Trust and the agent chooses Trustworthy, this yields ex-ante the highest sum of payoffs.

At the beginning of each session the recruited participants (invitees) were seated separate from their friends. A coin flip determined which group (invitees or friends) played the trust game

\footnotetext{
${ }^{7}$ The labels in Figure 1 are only used for illustrative purposes. In the experiment we used neutral labels.
} 


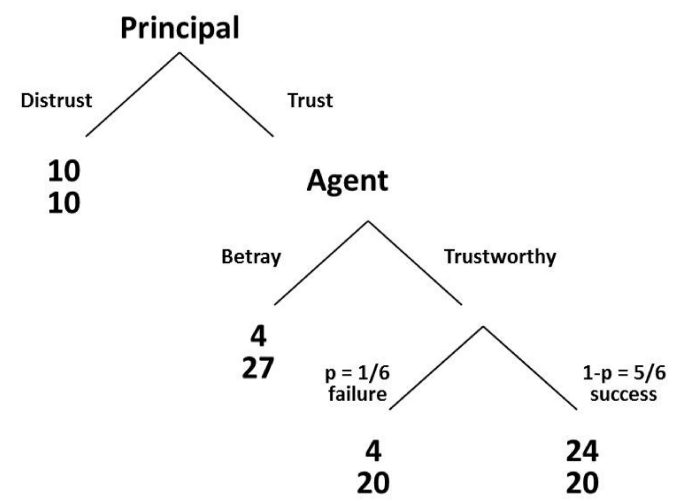

Figure 1: One-shot Binary Trust Game with Hidden Action for Agents (Payoffs in L.E.)

as a principal. Principals and agents made their decision simultaneously, that is, agents made their decision assuming a trusting principal. We thus obtained an observation for each agent. ${ }^{8}$

Each principal and each agent made two decisions; they played the game once with their friend (friend pairing) and once with some other randomly chosen person ("stranger") from the other group (stranger pairing). The order of the two decisions (stranger versus friend pairing) was randomized. We explained to participants that only the decision in one pairing (stranger or friend) would determine their payoff and that the relevant pairing would be randomly selected in public at the end of the session. Furthermore, if the stranger pairing was selected for payment, they knew they would also learn about the identity of the other player.

After making their decisions, principals were asked what decision they expected from both their friend and the stranger. This binary belief measure is easy to implement, but it likely captures less variation in principals' beliefs. ${ }^{9}$ However, given the high share of participants with no or little formal education, and the time constraints we faced, we refrained from eliciting principals' subjective probability of agents' trustworthiness. ${ }^{10}$

\footnotetext{
${ }^{8}$ After the agent made her decision in private, the assistant drew one of six numbered cards (1-6) to determine whether the principal would receive 24 L.E. $(p=5 / 6)$ or 4 L.E. $(p=1 / 6)$ in the event Trustworthy had been chosen.

${ }^{9}$ There may also be some measurement error if principals have different cutoff probabilities in mind when reporting their binary belief. Both issues will make it harder to trace any relationship between principals' stated beliefs and their actual choices. We will get back to this in section 3 when discussing the results.

${ }^{10}$ Recently, some progress has been made on measuring subjective expectations in developing countries - for example, by making the elicitation task more tangible through visual aids and less abstract formulations and by providing training and exercises beforehand. The implementation of these methods, however, requires substantial time and it is unclear how sensitive the elicited probabilities are to certain design choices, such as the form of the visual aid (for an excellent review see Delavande, Giné and McKenzie, 2011).
} 


\subsection{Dictator Games}

In the standard dictator game, a decision maker (i.e., the dictator) has to decide how to allocate a certain amount of money (20 L.E. in our study) between himself and a passive recipient. We modified the dictator game in order to measure other-regarding preferences for both principals and agents. To do so, we asked all participants to make an allocation decision, while their particular, randomly selected role (decision maker or recipient) was revealed to them only at the end of the session. ${ }^{11}$ Furthermore, and analog to the trust game, we collected allocation decisions for friends and strangers. That is, decision makers had to decide how much to transfer to a friend and how much to transfer to a stranger, while only one of the two decisions was randomly selected for payment.

Finally, participants played two versions of this modified dictator game. In the anonymous dictator game (DGA), the recipient did not learn about the identity of the decision maker. To ensure anonymity, we only revealed the assigned role (decision maker or recipient) after the session was over, but not whether the friend or the stranger pairing was chosen for payment. In view of the role uncertainty and the fact that giving cannot be motivated by potential future rewards, we refer to the motive of giving in the DGA as solidarity. In the non-anonymous treatment (DGNA), in contrast, the recipient learned about the identity of the decision maker at the end of the session. Due to the possibility of future interaction and enforcement, we refer to the motive of giving in the DGNA as reciprocity. We add the labels "stranger" and "friend" in order to specify whether we refer to the amount given to a stranger or to the friend in either of the dictator games (DGA or DGNA). ${ }^{12}$

\subsection{Empirical Model}

Making use of the within-subject design, we first estimate the following binary choice model for principals' propensity to trust:

$$
\text { Trust }_{i j}=\alpha+\beta_{1} \text { Friend }_{i j}+\beta_{2} \text { Exp }_{i j}+\beta_{3} \text { SocPref }_{i j}+\beta_{4} \text { RiskPref }_{i}+X_{i}^{\prime} \delta+\epsilon_{i j}
$$

\footnotetext{
${ }^{11}$ It is conceivable that this role uncertainty leads to higher transfers than in a standard dictator game with role certainty, as it may increase decision makers' awareness of, or empathy for, the plight of the recipient. Evidence supporting this hypothesis has recently been provided in Andreoni and Rao (2011). We should note, however, that our dictator game results (see Table 5) are well in line with previous findings for dictator games (with role certainty) in developing countries (see e.g., Cardenas and Carpenter, 2008; Ligon and Schechter, 2012).

${ }^{12}$ The non-anonymous treatment was inspired by the experimental design of Leider et al. (2009). Note that we randomized the order of the dictator games (DGA versus DGNA) as well as the order of the decisions (stranger versus friend pairing). Participants were paid for one decision in each game (DGA and DGNA).
} 
where Friend is a dummy variable equal to one for the friend pairing. Exp refers to the principal $i$ 's expectation that the agent - i.e., her friend $j$ or a stranger $j$ - will choose Trustworthy, which we elicited after the principal made her decisions (see Section 2.1). SocPref stands for other-regarding preferences, RiskPref for risk preferences, and $X_{i}$ for the principal's individual characteristics, i.e., age, gender and years of schooling. Additionally, we estimate a regression for the stranger and the friend pairing separately, in which we also control for the principal's social network (Net) and, in the case of the friend pairing, for the relationship to her friend (Friendship):

$$
\text { Trust }_{i}=\alpha+\beta_{1} \text { Exp }_{i}+\beta_{2} \text { SocPref }_{i}+\beta_{3} \text { RiskPref }_{i}+X_{i}^{\prime} \delta+\beta_{4} \text { Net }_{i}+\beta_{5} \text { Friendship }_{i}+\epsilon_{i}
$$

To control for other-regarding preferences we rely on participants' stranger and friend solidarity, as revealed in the anonymous dictator game (DGA). This measure is complemented with dummy variables indicating whether the participant volunteers for a non-profit organization and the frequency of lending money to friends (never, once or several times per year, or once a month or more). ${ }^{13}$ We anticipate a positive relationship between each of these variables and trust (e.g., Castillo and Carter, 2002; Ashraf, Bohnet and Piankov, 2006).

Risk preferences were elicited through an attitudinal question in the post-experimental questionnaire. ${ }^{14}$ The literature provides mixed evidence of the influence of risk attitudes on trust behavior (Eckel and Wilson, 2004; Karlan, 2005; Schechter, 2007; Houser, Schunk and Winter, 2010). For instance, Schechter (2007) finds a positive impact of risk on trusting behavior for rural villagers in Paraguay, whereas Houser, Schunk and Winter (2010) find that risk preferences, albeit explaining behavior in a risk game, have no explanatory power in the trust game.

General network characteristics may also affect trust (Glaeser et al., 2000; Karlan et al., 2009). We therefore control for the number of close friends aside from family members, the primary borrowing source and an individual's level of integration in her immediate neighborhood. We assume that having few close friends, borrowing money primarily from friends and relatives and perceiving neighbors as strangers (i.e., being less integrated in one's community) are indicators

\footnotetext{
${ }^{13}$ Note that these additional measures do not vary with social distance. Unless otherwise stated, all control variables are constructed from the data that we collected through an interview-based socio-economic questionnaire at the end of each session (see also section 2).

${ }^{14}$ Participants were asked the following question taken from the German Socio-Economic Panel: "How do you see yourself: Are you generally a person who is fully prepared to take risks or do you try to avoid taking risks?" Answers are given on a 11-point scale that ranges from risk avoidance ("0") to fully prepared to take risks ("10"). Dohmen et al. (2011) and Hardeweg, Menkhoff and Waibel (2011) validated the same risk question with experimental data from Germany and, respectively, rural Thailand. Ideally, we would have liked to elicit risk attitudes through actual behavior in a risk game (see e.g., Schechter, 2007; Bohnet, Herrmann and Zeckhauser, 2010), but we abstained from doing so since such a game could be associated with gambling, which is forbidden in Islam.
} 


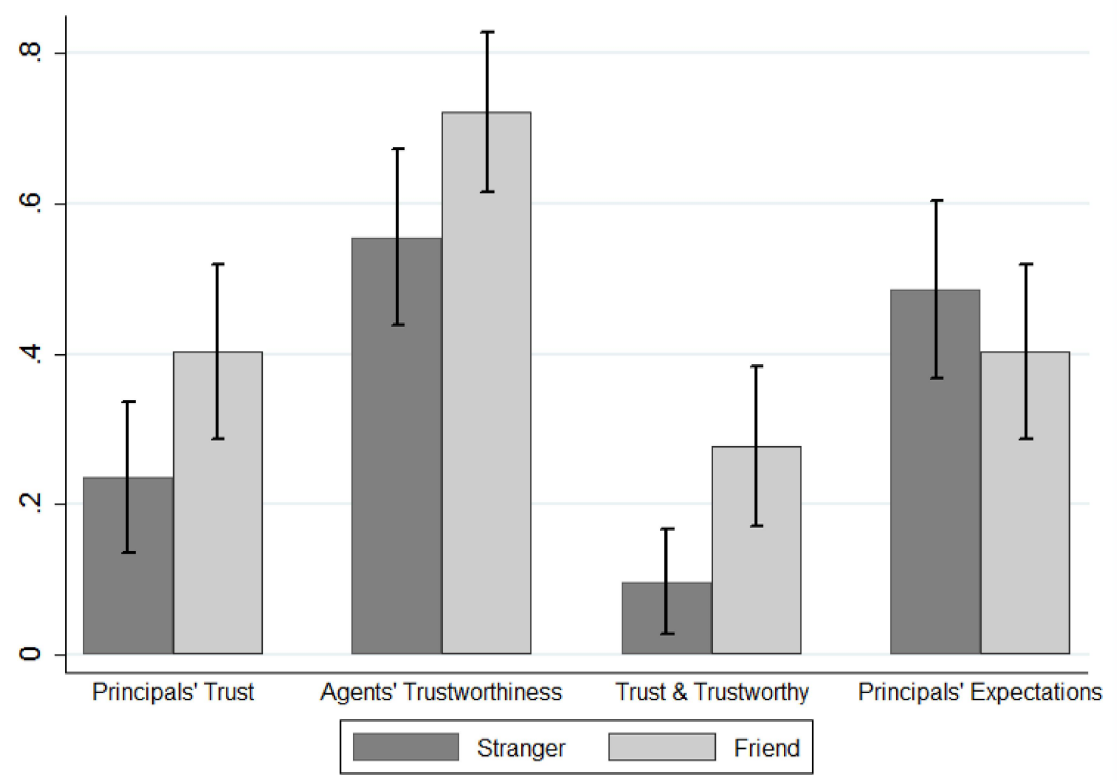

Figure 2: The Effect of Social Distance on Expectations and Behavior in the Trust Game.

of a higher dependence on existing relationships and thus for strong social ties. This is likely to be associated with a lower probability to trust strangers and a higher probability to trust friends (Ermisch and Gambetta, 2010; Alesina and Giuliano, 2011). ${ }^{15,16}$

Finally, to understand how repeated interaction between friends may foster trust (Homans, 1950; Kreps et al., 1982; Kranton, 1996; Marmaros and Sacerdote, 2006; Karlan et al., 2009), we use the frequency of interaction and the length of the relationship as proxies for the quality of a relationship.

\section{Experimental Results: Social Distance and the Determinants of Trust}

Figure 2 presents the aggregate results for the trust game. Only 17 out of 72 principals (24\%) chose Trust when confronted with a stranger. The trust rate increased substantially to $40 \%$ (29 out of 72) when principals were confronted with a socially close person (paired t-test $t_{(71)}=2.54$, $p<0.015)$. Albeit a principal is unable to determine the action chosen by the agent (Betray or Trustworthy), about 55\% of agents (40 out of 72) chose Trustworthy when the principal was a

\footnotetext{
${ }^{15}$ Given these different predictions for the friend and the stranger pairing, we do not include network characteristics $(N e t)$ in the panel regressions.

${ }^{16}$ Alesina and La Ferrara (2002) suggest that trust is influenced by how long an individual has lived in a community. Controlling for being born in Manshiet Nasser as an indicator for an individual's integration in her community instead of perceiving one's neighbors as strangers does not change our results qualitatively.
} 
Table 1: Principals' and Agents' Decisions in the Trust Game Conditional on the Principals' Expectations.

\begin{tabular}{llllllll}
\hline \hline \multirow{2}{*}{$\begin{array}{l}\text { Principals expecting } \\
\text { the agent to choose }\end{array}$} & & \multicolumn{2}{c}{$\begin{array}{c}\text { Share of principals } \\
\text { choosing }\end{array}$} & & \multicolumn{2}{c}{$\begin{array}{c}\text { Share of agents } \\
\text { choosing }\end{array}$} \\
\multirow{2}{*}{ Betray } & stranger & $(N=37)$ & 0.81 & 0.19 & & 0.46 & 0.54 \\
& friend & $(N=43)$ & 0.77 & 0.23 & & 0.26 & 0.74 \\
\hline \multirow{2}{*}{ Trustworthy } & stranger & $(N=35)$ & 0.71 & 0.29 & & 0.43 & 0.57 \\
& friend & $(N=29)$ & 0.34 & 0.66 & & 0.31 & 0.69 \\
\hline
\end{tabular}

stranger. This share increased to $72 \%$ (52 out of 72 ) when the principal was their friend (paired t-test $\left.t_{(71)}=2.54, p<0.015\right)$. Reduced social distance also led to a higher share of (Trust, Trustworthy) outcomes. When the principal and the agent did not know each other, only seven out of 72 pairs (10\%) succeeded in implementing the (Trust, Trustworthy) outcome compared to 20 pairs $(28 \%)$ when they knew each other. Even though the share of principals choosing Trust increased when they interacted with a friend, a substantial gap between trust and trustworthiness remained. A similar gap is also apparent between the share of principals expecting their friend to choose Trustworthy and the actual share of friends choosing Trustworthy. That is, principals tend to have too pessimistic expectations about the trustworthiness of their friends (paired t-test $t_{(71)}=3.94, p<0.01$ ), which is not the case for strangers (paired t-test $t_{(71)}=0.84, p>0.2$ ).

Table 1 provides a more detailed analysis of the actions taken by both the principals and agents conditional on the principals' expectations. The first two columns show the share of principals choosing Distrust or Trust in the friend and the stranger pairing conditional on their stated belief. The last two columns give the share of agents choosing Betray or Trustworthy, again conditional on principals' stated belief. The table illustrates that, first, principals who believe that the agent will choose Betray mostly choose Distrust, and this is the case in both the stranger pairing (81\%) and friend pairing (77\%). Second, principals who believe that the agent will choose Trustworthy are much more likely to choose Trust when the agent is their friend rather than a stranger $\left(\chi_{(1)}^{2}=8.74, p<0.01\right)$. Note also that in the friend pairing the share of principals choosing Trust increases from $23 \%$, when they expect their friend to choose Betray, to $66 \%$, when they expect their friend to choose Trustworthy. Third, the share of agents choosing Trustworthy in the friend pairing is remarkably high, irrespective of the principals' beliefs. While this means that principals who expect their friend to choose Trustworthy had "correct" expectations in $69 \%$ of cases, prin- 
cipals who expect their friend to choose Betray had "correct" expectations in only $26 \%$ of cases. This suggests that, based on our binary belief measure, principals have difficulties in forming accurate expectations of their friend's behavior. Interestingly, principals do not have more accurate expectations in the friend than in the stranger pairing (paired t-test $t_{(71)}=0.92, p>0.17$ ).

Following the empirical specifications in Section 2.3, Table 2 presents the estimation results for principals' propensity to trust. ${ }^{17}$ The estimates from the first two specifications in Table 2 confirm that a decrease in social distance leads to a statistically significant increase in the likelihood that principals choose Trust. Moreover, principals who expect the agent to choose Trustworthy are more likely to choose Trust. This relationship between the binary belief measure and trust, however, only holds true for the friend pairing (see column 3), which is consistent with the descriptive results presented in Table 1. Furthermore, differences in trust across the friend and the stranger pairing can be explained by the different role expectations play in the two pairings. A principal's solidarity, in contrast, is not significantly correlated on average with her trust decision. Results are similar when we add further controls for other-regarding and risk preferences and for individual characteristics (column 4).

The last three columns (columns 5-7) of Table 2 show the results separately for the stranger and the friend pairing. Column (5) reveals that only variables related to a principal's otherregarding preferences are significantly correlated with her decision to trust a stranger. More specifically, the frequency of lending money and volunteering significantly increase the probability that principals choose Trust when paired with a stranger and these two coefficients and the coefficient on stranger solidarity are jointly significant. ${ }^{18}$ While there is no economically and statistically significant association between principals' stated belief and trust in strangers, principals who expect their friend to choose Trustworthy are .47 to .49 more likely to choose Trust, which is also statistically significant. In the last column, we additionally control for differences in friendship characteristics. However, neither coefficient is statistically significant.

Overall, the results suggest that principals are more likely to follow their stated belief when interacting with a socially close person as compared to a stranger. However, since we do not have information about the underlying belief distribution(s), it could be the case, for example, that principals state that they expect both their friend and a stranger to choose the same action, e.g.,

\footnotetext{
${ }^{17}$ The summary statistics for the dictator games and for participants' network and friendship characteristics are presented in Appendix Table 5. A more detailed discussion of the dictator game results is available in Binzel and Fehr (2010).

${ }^{18} \mathrm{~A}$ Wald test is significant at the 5 percent level $\left(\chi_{(3)}^{2}=9.9, p<0.02\right)$. The same test is not significant for the friend pairing $\left(\chi_{(3)}^{2}=3.5, p>0.33\right)$.
} 
Table 2: Determinants of Principals' Behavior in the Trust Game.

\begin{tabular}{|c|c|c|c|c|c|c|c|}
\hline & $\begin{array}{c}(1) \\
\text { Panel } \\
\end{array}$ & $\begin{array}{c}\text { ependent } \\
(2) \\
\text { Panel } \\
\end{array}$ & $\begin{array}{c}\text { variable: } \\
(3) \\
\text { Panel } \\
\end{array}$ & $\begin{array}{c}\text { Principals } \\
(4) \\
\text { Panel } \\
\end{array}$ & $\begin{array}{c}\text { decision } \\
\text { (5) } \\
\text { Stranger }\end{array}$ & $\begin{array}{c}\text { trust (d) } \\
(6) \\
\text { Friend } \\
\end{array}$ & $\begin{array}{c}(7) \\
\text { Friend }\end{array}$ \\
\hline Paired with friend (d) & $\begin{array}{l}0.204 * * \\
(0.082)\end{array}$ & $\begin{array}{l}0.223 * * * \\
(0.083)\end{array}$ & $\begin{array}{c}0.039 \\
(0.123)\end{array}$ & $\begin{array}{c}0.047 \\
(0.123)\end{array}$ & & & \\
\hline $\begin{array}{l}\text { Principal expects the agent to } \\
\text { choose Trustworthy (d) }\end{array}$ & & $\begin{array}{l}0.273 * * * \\
(0.092)\end{array}$ & $\begin{array}{c}0.066 \\
(0.139)\end{array}$ & $\begin{array}{c}0.100 \\
(0.143)\end{array}$ & $\begin{array}{c}0.122 \\
(0.097)\end{array}$ & $\begin{array}{l}0.491 * * * \\
(0.119)\end{array}$ & $\begin{array}{l}0.474 * * * \\
(0.123)\end{array}$ \\
\hline $\begin{array}{l}\text { Interaction: Paired with friend } \mathrm{x} \\
\text { Principal's expectations }\end{array}$ & & & $\begin{array}{c}0.441 * \\
(0.232)\end{array}$ & $\begin{array}{r}0.430 * \\
(0.231)\end{array}$ & & & \\
\hline \multicolumn{8}{|l|}{ Other-regarding preferences: } \\
\hline $\begin{array}{l}\text { Stranger/friend solidarity } \\
\text { (Transfer in DGA) }\end{array}$ & & $\begin{array}{c}0.012 \\
(0.016)\end{array}$ & $\begin{array}{c}0.010 \\
(0.017)\end{array}$ & $\begin{array}{c}0.006 \\
(0.016)\end{array}$ & $\begin{array}{r}-0.003 \\
(0.014)\end{array}$ & $\begin{array}{c}0.008 \\
(0.019)\end{array}$ & $\begin{array}{c}0.009 \\
(0.019)\end{array}$ \\
\hline Volunteer for NGO (d) & & & & $\begin{array}{c}0.284 * \\
(0.146)\end{array}$ & $\begin{array}{r}0.270 * \\
(0.146)\end{array}$ & $\begin{array}{c}0.241 * \\
(0.144)\end{array}$ & $\begin{array}{c}0.231 \\
(0.150)\end{array}$ \\
\hline Frequency of lending & & & & $\begin{array}{c}0.114 \\
(0.074)\end{array}$ & $\begin{array}{l}0.170 * * \\
(0.070)\end{array}$ & $\begin{array}{c}0.030 \\
(0.093)\end{array}$ & $\begin{array}{c}0.024 \\
(0.095)\end{array}$ \\
\hline Risk preferences & & & & $\begin{array}{c}0.001 \\
(0.016)\end{array}$ & $\begin{array}{c}-0.007 \\
(0.014)\end{array}$ & $\begin{array}{c}0.007 \\
(0.019)\end{array}$ & $\begin{array}{c}0.008 \\
(0.019)\end{array}$ \\
\hline \multicolumn{8}{|l|}{ Individual characteristics: } \\
\hline Age & & & & $\begin{array}{r}-0.002 \\
(0.006)\end{array}$ & $\begin{array}{c}0.000 \\
(0.006)\end{array}$ & $\begin{array}{r}-0.000 \\
(0.007)\end{array}$ & $\begin{array}{r}-0.001 \\
(0.008)\end{array}$ \\
\hline Female (d) & & & & $\begin{array}{r}-0.046 \\
(0.109)\end{array}$ & $\begin{array}{r}-0.055 \\
(0.102)\end{array}$ & $\begin{array}{r}-0.056 \\
(0.145)\end{array}$ & $\begin{array}{r}-0.075 \\
(0.157)\end{array}$ \\
\hline Years of Schooling & & & & $\begin{array}{r}-0.013 \\
(0.013)\end{array}$ & $\begin{array}{r}-0.013 \\
(0.012)\end{array}$ & $\begin{array}{r}-0.012 \\
(0.015)\end{array}$ & $\begin{array}{r}-0.010 \\
(0.014)\end{array}$ \\
\hline \multicolumn{8}{|l|}{ Social network characteristics: } \\
\hline Close friends $(\#)$ & & & & & $\begin{array}{r}-0.007 \\
(0.005)\end{array}$ & $\begin{array}{r}-0.011 \\
(0.007)\end{array}$ & $\begin{array}{r}-0.012 \\
(0.008)\end{array}$ \\
\hline Borrowing within network (d) & & & & & $\begin{array}{r}-0.017 \\
(0.109)\end{array}$ & $\begin{array}{c}0.162 \\
(0.140)\end{array}$ & $\begin{array}{c}0.158 \\
(0.138)\end{array}$ \\
\hline Neighbors like strangers (d) & & & & & $\begin{array}{r}-0.143 \\
(0.082)\end{array}$ & $\begin{array}{c}0.264 * \\
(0.143)\end{array}$ & $\begin{array}{c}0.272 * \\
(0.142)\end{array}$ \\
\hline \multicolumn{8}{|l|}{ Friendship characteristics: } \\
\hline Daily visits (d) & & & & & & & $\begin{array}{r}-0.086 \\
(0.155)\end{array}$ \\
\hline Long-term relation $(\mathrm{d})$ & & & & & & & $\begin{array}{c}-0.082 \\
(0.122)\end{array}$ \\
\hline $\mathrm{N}$ & 144 & 144 & 144 & 144 & 72 & 72 & 72 \\
\hline Pseudo $\mathrm{R}^{2}$ & & & & & 0.17 & 0.22 & 0.22 \\
\hline
\end{tabular}

(d) dummy variable. ${ }^{*} \mathrm{p}<0.10,{ }^{* *} \mathrm{p}<0.05, * * * \mathrm{p}<0.01$

Marginal effects are reported with standard errors in parentheses from estimating random-effects probit models (columns 1-4) and simple probit models (columns 5-7) for the probability that the principal opts for trust. "Stranger" refers to the stranger pairing; "friend" to the friend pairing. Standard errors in columns (5) to (7) are heteroskedasticity-robust. "Frequency of lending" is a categorical variable for lending money (never, once/several times per year, or once per month or more). "Risk preferences" refers to an 11-point scale ranging from trying to avoid risks ("0") to fully prepared to take risks ("10"). "Close friends (\#)" is the number of close friends besides the family and "borrowing within network" indicates whether the first two sources of borrowing money are family and close friends. "Neighbors like strangers" indicates the perception of immediate neighbors, while "long-term relation" indicates whether friends know each other for 5 years or longer. 
Trustworthy, even though they have different likelihoods of choosing Trustworthy for their friend and a stranger in mind (see also section 2.1). In order to gain some additional insights, we draw on the principals' expectations about their friend's and a stranger's transfer in the DGNA, which provide us with a continuous measure in contrast to the binary measure in the trust game. We find evidence that principals who correctly predict their friend's transfer in the DGNA are significantly more likely to choose an action in the trust game that is in line with their binary belief than principals with accurate expectations about a stranger's transfer. ${ }^{19}$ This may suggest that in the trust game principals are indeed more confident in their stated binary belief when the agent is their friend. When the agent is a stranger, principals seem uncertain about what to expect; they are split almost equally between expecting the agent to be trustworthy and not expecting her to be trustworthy (see Figure 2). It may then come at little surprise that their beliefs have little predictive power for their decision to trust and that other-regarding preferences become more important.

\section{Expected and Actual Trustworthiness}

The previous analysis suggests that expectations are a key determinant of trust among socially close persons. Yet, as illustrated in Figure 2 and Table 1, principals underestimate their friends' trustworthiness, so that a substantial share of principals forgoes the opportunity of a high payoff by realizing the (Trust, Trustworthy) outcome. In an attempt to understand why this may be the case, we examine the determinants for agents' trustworthiness by estimating models similar to those for principals' decision to trust (see Section 2.3). We then ask which of these determinants principals incorporate into their expectations.

Columns (1) to (6) in Table 3 show the estimation results for modeling agents' trustworthiness. Without controlling for other factors (column 1), we find that the average increase in the agent's likelihood to choose Trustworthy following a reduction in social distance is similar in size and statistical significance to the principal's response to a change in social distance. Once we include the amount given in the DGA, we find that differences in trustworthiness toward strangers and friends can be fully explained by differences in agents' solidarity toward strangers and friends. ${ }^{20}$ Each additional Egyptian pound the agent gives in the DGA increases the agent's probability of choosing Trustworthy by about .06 on average. This positive correlation between agents' solidarity

\footnotetext{
${ }^{19}$ The corresponding $\chi^{2}$-test statistic is significant at the $1 \%$ level $\left(\chi_{(1)}^{2}=7.72, p<0.01\right)$. We thank an anonymous referee for suggesting the essence of this analysis.

${ }^{20}$ Indeed, in the DGA, agents' transfers to friends (44\%) are significantly larger than their transfers to strangers $(36 \%)$. Running a paired t-test yields a $p<0.01$ for reduction in social distance in the DGA.
} 
Table 3: Determinants of Agents' Behavior and Principals' Expectations in the Trust Game.

\begin{tabular}{|c|c|c|c|c|c|c|c|}
\hline \multirow[t]{3}{*}{ Dependent variable: } & \multicolumn{6}{|c|}{ Agents' decision to be trustworthy (d) } & \multirow{3}{*}{$\begin{array}{c}\text { Principals' } \\
\text { expectation (d) } \\
(7) \\
\text { Friend }\end{array}$} \\
\hline & $(1)$ & $(2)$ & $(3)$ & (4) & $(5)$ & (6) & \\
\hline & Panel & Panel & Panel & Stranger & Friend & Friend & \\
\hline Paired with friend (d) & $\begin{array}{l}0.221 * * \\
(0.089)\end{array}$ & $\begin{array}{c}0.114 \\
(0.092)\end{array}$ & $\begin{array}{c}0.125 \\
(0.093)\end{array}$ & & & & \\
\hline \multicolumn{8}{|l|}{ Other-regarding preferences: } \\
\hline $\begin{array}{l}\text { Stranger/friend solidarity } \\
\text { (Transfer in DGA) }\end{array}$ & & $\begin{array}{l}0.061 * * * \\
(0.017)\end{array}$ & $\begin{array}{l}0.056 * * * \\
(0.018)\end{array}$ & $\begin{array}{l}0.070 * * * \\
(0.020)\end{array}$ & $\begin{array}{l}0.070 * * * \\
(0.024)\end{array}$ & $\begin{array}{l}0.077 * * * \\
(0.023)\end{array}$ & $\begin{array}{r}-0.030 \\
(0.020)\end{array}$ \\
\hline Volunteer $(\mathrm{d})$ & & & $\begin{array}{c}0.016 \\
(0.134)\end{array}$ & $\begin{array}{c}-0.152 \\
(0.152)\end{array}$ & $\begin{array}{c}0.104 \\
(0.100)\end{array}$ & $\begin{array}{c}0.138 \\
(0.103)\end{array}$ & $\begin{array}{r}0.270 * \\
(0.153)\end{array}$ \\
\hline Frequency of lending & & & $\begin{array}{c}0.022 \\
(0.072)\end{array}$ & $\begin{array}{r}-0.051 \\
(0.087)\end{array}$ & $\begin{array}{c}0.028 \\
(0.065)\end{array}$ & $\begin{array}{c}0.052 \\
(0.067)\end{array}$ & $\begin{array}{c}0.062 \\
(0.088)\end{array}$ \\
\hline Risk preferences & & & $\begin{array}{c}0.008 \\
(0.015)\end{array}$ & $\begin{array}{c}0.021 \\
(0.018)\end{array}$ & $\begin{array}{r}-0.010 \\
(0.016)\end{array}$ & $\begin{array}{r}-0.018 \\
(0.016)\end{array}$ & $\begin{array}{l}(0.017) \\
(0.019)\end{array}$ \\
\hline \multicolumn{8}{|l|}{ Individual characteristics: } \\
\hline Age & & & $\begin{array}{c}0.010 \\
(0.006)\end{array}$ & $\begin{array}{r}0.013 * \\
(0.008)\end{array}$ & $\begin{array}{c}0.002 \\
(0.006)\end{array}$ & $\begin{array}{r}-0.000 \\
(0.006)\end{array}$ & $\begin{array}{r}-0.008 \\
(0.007)\end{array}$ \\
\hline Female (d) & & & $\begin{array}{c}-0.034 \\
(0.111)\end{array}$ & $\begin{array}{r}-0.116 \\
(0.130)\end{array}$ & $\begin{array}{c}0.041 \\
(0.111)\end{array}$ & $\begin{array}{c}0.081 \\
(0.113)\end{array}$ & $\begin{array}{l}0.289 * * \\
(0.113)\end{array}$ \\
\hline Years of Schooling & & & $\begin{array}{c}0.015 \\
(0.013)\end{array}$ & $\begin{array}{c}0.022 \\
(0.016)\end{array}$ & $\begin{array}{c}0.009 \\
(0.013)\end{array}$ & $\begin{array}{c}0.008 \\
(0.012)\end{array}$ & $\begin{array}{c}-0.021 \\
(0.017)\end{array}$ \\
\hline \multicolumn{8}{|l|}{ Social network characteristics: } \\
\hline Close friends $(\#)$ & & & & $\begin{array}{r}-0.004 \\
(0.004)\end{array}$ & $\begin{array}{r}0.005 * \\
(0.003)\end{array}$ & $\begin{array}{c}0.004 \\
(0.002)\end{array}$ & $\begin{array}{l}-0.016 * * \\
(0.008)\end{array}$ \\
\hline Borrowing within network (d) & & & & $\begin{array}{r}-0.156 \\
(0.139)\end{array}$ & $\begin{array}{c}0.146 \\
(0.125)\end{array}$ & $\begin{array}{c}0.086 \\
(0.124)\end{array}$ & $\begin{array}{c}-0.139 \\
(0.132)\end{array}$ \\
\hline Neighbors like strangers $(\mathrm{d})$ & & & & $\begin{array}{c}0.250 * \\
(0.137)\end{array}$ & $\begin{array}{l}0.277 * * * \\
(0.091)\end{array}$ & $\begin{array}{l}0.292 * * * \\
(0.084)\end{array}$ & $\begin{array}{c}0.293 * * \\
(0.145)\end{array}$ \\
\hline \multicolumn{8}{|l|}{ Friendship characteristics: } \\
\hline Daily visits (d) & & & & & & $\begin{array}{l}0.250 * * \\
(0.119)\end{array}$ & \\
\hline Long-term relation $(\mathrm{d})$ & & & & & & $\begin{array}{c}0.094 \\
(0.107)\end{array}$ & \\
\hline $\mathrm{N}$ & 144 & 144 & 144 & 72 & 72 & 72 & 72 \\
\hline Pseudo $\mathrm{R}^{2}$ & & & & 0.21 & 0.26 & 0.32 & 0.20 \\
\hline
\end{tabular}

(d) dummy variable. ${ }^{*} \mathrm{p}<0.10, * * \mathrm{p}<0.05, * * * \mathrm{p}<0.01$

Marginal effects are reported with standard errors in parentheses from estimating random-effects probit models (columns 1-3) and probit models (columns 4-6) for the probability that an agent opts for Trustworthy and from estimating a probit model for the probability that a principal expects her friend to choose Trustworthy (column 7). "Stranger" refers to the stranger pairing; "friend" to the friend pairing. Standard errors in columns (4)-(7) are heteroskedasticity-robust. "Frequency of lending" is a categorical variable for lending money (never, once/several times per year, or once per month or more). "Risk preferences" refers to an 11-point scale ranging from trying to avoid risks ("0") to fully prepared to take risks ("10"). "Close friends (\#)" is the number of close friends besides the family and "borrowing within network" indicates whether the first two sources of borrowing money are family and close friends. "Neighbors like strangers" indicates the perception of immediate neighbors, while "long-term relation" indicates whether friends know each other for 5 years or longer. The variables in column (7), except age, female and years of schooling, refer to the characteristics of the friend. 
and agents' decision to be trustworthy is also reflected in the regressions using data only from the stranger (column 4) or from the friend pairing (columns 5 and 6), and is in line with previous evidence from trust games with strangers (e.g., Castillo and Carter, 2002; Ashraf, Bohnet and Piankov, 2006). Furthermore, whereas friendship characteristics do not explain variation in trust among friends, agents are more likely to choose Trustworthy if they see their friend on a daily basis (column 6). Thus, more frequent interaction between friends may increase the cost of lying and, in turn, reduce agents' willingness to choose Betray.

Based on the findings above, we may assume that principals expect that friends who exhibit greater friend solidarity are more likely to choose Trustworthy. To test this, we now turn to the principals' expectations of agents' trustworthiness (Table 3, column 7). The regression uses the actual characteristics of the friend as explanatory variables, which we take as a proxy for the principals' assessment of their friend, while also controlling for the principals' individual characteristics. ${ }^{21}$

The regression results reveal that principals' expectations in the trust game are not statistically significantly correlated with their friend's solidarity. More generally, there is no statistically significant correlation between principals' expectations and their friend's other-regarding preferences as the coefficients for volunteering, lending money and friend solidarity are jointly insignificant (Wald test $\chi_{(3)}^{2}=4.94, p=0.18$ ). Nevertheless, principals seem to recognize that having more close friends may reduce trustworthiness and that less integrated friends, i.e., friends with limited outside options and thus greater dependence on established relationships, are more likely to be trustworthy. The results also indicate that female principals are significantly more likely to expect their friends to be trustworthy. This could reflect general characteristics of female principals or agents, but it may equally be the case that female pairs are different from male pairs. ${ }^{22}$

The preceeding analysis hinges, of course, on the assumption that principals can asses their friend's characteristics sufficiently well. This assumption may not be too farfetched, at least with regard to more observable characteristics, such as whether their friend volunteers for an NGO. ${ }^{23}$

\footnotetext{
${ }^{21}$ Principal's risk and other-regarding preferences should not affect the formation of beliefs (see Fehr, 2009; Naef et al., 2009).

${ }^{22}$ For instance, informal savings groups called gam'iyyaat (Singerman, 1995) are predominantly organized by women in the informal housing areas, and this requires a good ability to assess people. Furthermore, there is empirical evidence from microfinance programs and informal savings groups that women exhibit higher repayment rates than men (Morduch, 1999; Anderson and Baland, 2002). That is, independent from the principal's gender, principals may expect higher levels of trustworthiness from a female agent. Unfortunately, our study design does not allow us to examine this question more thoroughly.

${ }^{23}$ Also, in the non-anonymous dictator game (DGNA), a substantial fraction of principals (63\%) correctly predict the amount that their friend transfers to them. Principals also have more accurate expectations about their friends' transfer than about the transfer from a stranger as the difference between the expected and the actual transfer is significantly smaller in the friend pairing than in the stranger pairing (paired t-test $t_{(71)}=3.99, p<0.01$ ).
} 
However, the finding that principals' expectations in the trust game are not significantly correlated with their friend's solidarity could also be due to an inaccurate assessment of their friend's solidarity. Nonetheless, our results support the idea expressed in Wydick (2008), among others, that low trust and, more generally, lower levels of economic development, may be related to the inability of agents to successfully signal, or communicate, their trustworthiness. While the literature has so far focused on trust in strangers, our results indicate that this may also matter for trust within a given social network in environments where solidarity norms are strong.

\section{Conclusions}

Understanding the determinants of trust toward strangers in relation to socially close persons is of possible importance for the formulation of policies in environments with weak formal institutions. Based on a binary trust game with hidden action, which we implemented in a lab-in-the-field experiment in Cairo, we find that an increase in trust following a decrease in social distance is related to the principals' beliefs: the expectation that an agent will choose Trustworthy is associated with a greater probability to choose Trust among friends but not among strangers. Principals thus seem to face difficulties in forming expectations when interacting with strangers and, consequently, put less weight on their beliefs in the decision making process. They may also have less precise beliefs about the trustworthiness of a stranger as compared to a friend. We do not find any evidence that higher trust among friends is due to greater solidarity. Rather, it seems that other-regarding preferences play a greater role in the decision to trust when there is uncertainty about the agent's behavior as in the stranger pairing. From a policy perspective, our results suggest that trust may be fostered through changing beliefs. Previous research has shown that information policies can, for example, affect an individual's perceived returns to education (Jensen, 2010). How beliefs about trustworthiness may be changed, however, and, for instance, which role prior beliefs may play in building up trust are areas for future research.

Despite the increase in trust, we observe a significant gap between trust and trustworthiness among friends as well as between a principal's expectation about her friend's trustworthiness and her friend's actual trustworthiness. Because principals who choose to distrust are unable to learn whether their lack of trust was justified, a self-reinforcing cycle may set in, preventing trusting behavior in future transactions. Such a dynamic seems particularly likely in environments characterized by strong solidarity norms, in which costs to credibly signal one's trustworthiness are 
likely high. This may explain why we observe a relatively low willingness among friends to trust when enforcement mechanisms are absent, even though most friend pairs had known each other for several years.

The fact that principals underestimate their friend's trustworthiness suggests that social networks may be unable to completely resolve inefficiencies due to information asymmetries. On a more general level, our results may thus provide a further explanation for why social networks are not a perfect substitute for formal institutions: not only is trade essentially limited to members of a given social network (e.g., Munshi, 2006), economic exchanges within a network may only take place when transactions require little trust. 


\section{References}

Alesina, Alberto, and Eliana La Ferrara. 2002. "Who Trusts Others?" Journal of Public Economics, 85: 207-234.

Alesina, Alberto, and Paola Giuliano. 2011. "Family Ties and Political Participation." Journal of the European Economic Association, 9(5): 817-839.

Anderson, Siwan, and Jean-Marie Baland. 2002. "The Economics of Roscas and Intrahousehold Resource Allocation." Quarterly Journal of Economics, 117(3): 963-995.

Andreoni, James, and Justin M. Rao. 2011. "The Power of Asking: How Communication Affects Selfishness, Empathy, and Altruism." Journal of Public Economics, 95(7-8): 513-520.

Ashraf, Nava, Iris Bohnet, and Nikita Piankov. 2006. "Decomposing Trust and Trustworthiness." Experimental Economics, 9(3): 193-208.

Barr, Abigail. 2003. "Trust and Expected Trustworthiness: Experimental Evidence from Zimbabwean Villages." Economic Journal, 113(489): 614-630.

Berg, Joyce, John Dickhaut, and Kevin McCabe. 1995. "Trust, Reciprocity, and Social History." Games and Economic Behavior, 10(1): 122-142.

Binzel, Christine, and Dietmar Fehr. 2010. "Social Relationships and Trust: Experimental Evidence from a Slum in Cairo." SFB 649 Discussion Paper 2010-028.

Bohnet, Iris, and Bruno S. Frey. 1999. "Social Distance and Other-Regarding Behavior in Dictator Games: Comment." American Economic Review, 89(1): 335-339.

Bohnet, Iris, Benedikt Herrmann, and Richard Zeckhauser. 2010. "Trust and the Reference points for Trustworthiness in Gulf and Western Countries." Quarterly Journal of Economics, 125(2): 811-828.

Brañas-Garza, Pablo, Ramón Cobo-Reyes, María Paz Espinosa, Natalia Jiménez, Jaromir Kovarik, and Giovanni Ponti. 2010. "Altruism and Social Integration." Games and Economic Behavior, 69(2): 249 - 257.

Cardenas, Juan Camilo, Alberto Chong, Hugo Ñopo, Andrew W. Horowitz, and Daniel Lederman. 2009. "To What Extent Do Latin Americans Trust, Reciprocate, and Cooperate? Evidence from Experiments in Six Latin American Countries." Economía, 9(2): 45-94. 
Cardenas, Juan Camilo, and Jeffrey Carpenter. 2008. "Behavioural Development Economics: Lessons from Field Labs in the Developing World." Journal of Development Studies, 44(3): 311338.

Castillo, Marco, and Michael R. Carter. 2002. "The Economic Impacts of Altruism, Trust and Reciprocity: An Experimental Approach to Social Capital." mimeo.

Charness, Gary, and Martin Dufwenberg. 2006. "Promises and Partnership." Econometrica, 74(6): 1579-1601.

Coleman, James. 1990. Foundations of Social Theory. Cambridge:Belknapp Harvard.

Cox, Donald, and Marcel Fafchamps. 2008. "Extended Family and Kinship Networks: Economic Insights and Evolutionary Directions." In Handbook of Development Economics. Vol. 4, , ed. Paul T. Schultz and John A. Strauss, Chapter 58, 3711-3784. Elsevier.

Delavande, Adeline, Xavier Giné, and David McKenzie. 2011. "Measuring Subjective Expectations in Developing Countries: A Critical Review and New Evidence." Journal of Development Economics, 94(2): 151-163.

D'Exelle, Ben, and Arno Riedl. 2010. "Directed Generosity and Network Formation: Network Dimension Matters." IZA Discussion Paper 5356.

Dohmen, Thomas, Armin Falk, David Huffman, Uwe Sunde, Jürgen Schupp, and Gert G. Wagner. 2011. "Individual Risk Attitudes: Measurement, Determinants, and Behavioral Consequences." Journal of the European Economic Association, 9.

Eckel, Catherine, and Rick Wilson. 2004. "Is Trust a Risky Decision?" Journal of Economic Behavior and Organization, 55(4): 447-465.

Ermisch, John, and Diego Gambetta. 2010. "Do Strong Family Ties Inhibit Trust?" Journal of Economic Behavior 63 Organization, 75(3): 365-376.

Fafchamps, Marcel. 1992. "Solidarity Networks in Preindustrial Societies: Rational Peasants with a Moral Economy." Economic Development and Cultural Change, 41(1): 147-174.

Fehr, Ernst. 2009. "On The Economics and Biology of Trust." Journal of the European Economic Association, 7(2-3): 235-266. 
Foster, Andrew D., and Mark R. Rosenzweig. 2001. "Imperfect Commitment, Altruism, and the Family: Evidence from Transfer Behavior in Low-Income Rural Areas." Review of Economics and Statistics, 83(3): 389-407.

Glaeser, Edward L., David Laibson, Jose Scheinkman, and Christine Soutter. 2000. "Measuring Trust." Quarterly Journal of Economics, 115(3): 811-846.

Goeree, Jacob, Margaret Mcconnell, Tiffany Mitchell, Tracey Tromp, and Leeat Yariv. 2010. "The 1/d Law of Giving." American Economic Journal: Microeconomics, 2(1): 183-203.

Hardeweg, Bernd, Lukas Menkhoff, and Hermann Waibel. 2011. "Experimentally-validated Survey Evidence on Individual Risk Attitudes in Rural Thailand." Discussion Paper, Department of Economics, Leibnitz University of Hannover 464.

Hoffman, Elizabeth, Kevin McCabe, and Vernon L Smith. 1996. "Social Distance and Other-Regarding Behavior in Dictator Games." American Economic Review, 86(3): 653-660.

Homans, George C. 1950. The Human Group. New York:Harpers.

Houser, Daniel, Daniel Schunk, and Joachim Winter. 2010. "Distinguishing Trust from Risk: An Anatomy of the Investment Game." Journal of Economic Behavior and Organization, 74: $72-81$.

Jackson, Matthew O. 2008. Social and Economic Networks. Princeton:Princeton University Press.

Jensen, Robert. 2010. "The (Perceived) Returns to Education and the Demand for Schooling." Quarterly Journal of Economics, 2(125): 515-548.

Karlan, Dean S. 2005. "Using Experimental Economics to Measure Social Capital and Predict Financial Decisions." American Economic Review, 95(5): 1688-1699.

Karlan, Dean S. 2007. "Social Connections and Group Banking." Economic Journal, 117: 52-84.

Karlan, Dean S., Markus M. Möbius, Tanya Rosenblat, and Adam Szeidl. 2009. "Trust and Social Collateral." Quarterly Journal of Economics, 124(3): 1307-1361.

Knack, Stephen, and Philip Keefer. 1997. "Does Social Capital Have an Economic Payoff? A Cross-Country Investigation." Quarterly Journal of Economics, 112(4): 1251-1288. 
Kranton, Rachel E. 1996. "Reciprocal Exchange: A Self-Sustaining System." American Economic Review, 86(4): 830-851.

Kreps, David M., Paul Milgrom, John Roberts, and Robert Wilson. 1982. "Rational Cooperation in the Finitely Repeated Prisoners' Dilemma." Journal of Economic Theory, 27: 245252.

Leider, Stephen, Markus M. Möbius, Tanya Rosenblat, and Quoc-Anh Do. 2009. "Directed Altruism and Enforced Reciprocity in Social Networks." Quarterly Journal of Economics, 124(4): 1815-1851.

Ligon, Ethan, and Laura Schechter. 2012. "Motives for Sharing in Social Networks." Journal of Development Economics, 99(1): 13-26.

Marmaros, David, and Bruce Sacerdote. 2006. "How Do Friendships Form?" Quarterly Journal of Economics, 121(1): 79-119.

Morduch, Jonathan. 1999. "The Microfinance Promise." Journal of Economic Literature, 37(4): 1569-1614.

Munshi, Kaivan. 2006. "Nonmarket Institutions." In Understanding Poverty. , ed. Abhijit Vinayak Banerjee, Roland Bénabou and Dilip Mookherjee, Chapter 26, 389-399. New York:Oxford University Press.

Naef, Michael, Ernst Fehr, Urs Fischbacher, Jürgen Schupp, and Gert G. Wagner. 2009. "Decomposing Trust: Explaining National and Ethnical Trust Differences." mimeo.

Schechter, Laura. 2007. "Traditional Trust Measurement and the Risk Confound: An Experiment in Rural Paraguay." Journal of Economic Behavior and Organization, 62(2): 272-292.

Singerman, Diana. 1995. Avenues of Participation: Family, Politics, and Networks in Urban Quarters of Cairo. Princeton:Princeton University Press.

Sobel, Joel. 2002. "Can We Trust Social Capital?" Journal of Economic Literature, XL(March): 139-154.

Wydick, Bruce. 2008. Games in Economic Development. Cambridge, New York:Cambridge University Press. 


\section{A Appendix}

Table 4: Participants' Characteristics.

\begin{tabular}{lccccc}
\hline \hline Variable & N & Mean & Std. Dev. & Min & Max \\
\hline Female & 144 & $53 \%$ & & & \\
Muslim & 144 & $94 \%$ & & & \\
Born in Manshiet Nasser & 144 & $39 \%$ & & & 64 \\
Age & 144 & 30 & 11 & 17 & 16 \\
\hline Years of schooling & 144 & 9 & 6 & 0 & \\
Illiteracy & 144 & $31 \%$ & & & \\
Innumeracy & 144 & $12 \%$ & & & \\
Ever-married & 144 & $53 \%$ & & & \\
\hline Volunteer & 144 & $29 \%$ & & & 10 \\
Frequency of lending & 144 & 2.10 & 0.79 & 1 & 8 \\
Risk preferences & 144 & 5.68 & 3.71 & 0 & 10 \\
Wage income (in L.E.) & 59 & 377 & 263 & 70 & 6 \\
\hline Nr of children & 64 & 3 & 2 & 1 & 1 \\
Nr of siblings & 144 & 5 & 2 & 0 & 1 \\
Nr of persons per household & 144 & 6 & 2 & 1 & \\
Rooms per household & 144 & 3 & 1 & 1 & \\
\hline
\end{tabular}

"Volunteer" indicates volunteering for an NGO and "frequency of lending" is a categorical variable for lending money (never, once/several times per year, or once per month or more). "Risk preferences" refers to an 11-point scale ranging from trying to avoid risks ("0") to fully prepared to take risks ("10"). 
Table 5: Summary Statistics for the Dictator Games and for Participants' Network and Friendship Characteristics $(N=144)$.

\begin{tabular}{lcc}
\hline \hline Explanatory Variable & Mean & Std. Dev. \\
\hline Anonymous dictator game: & & \\
Amount given to a stranger (stranger solidarity) & 7.29 & 3.55 \\
Amount given to the friend (friend solidarity) & 8.85 & 3.12 \\
Non-anonymous dictator game: & & \\
Amount given to a stranger (stranger reciprocity) & 7.90 & 3.10 \\
Amount given to the friend (friend reciprocity) & 9.21 & 2.60 \\
Expected amount from a stranger & 6.67 & 2.99 \\
Expected amount from their friend & 9.26 & 2.66 \\
\hline Close friends (\#) & 4.75 & 11.17 \\
Borrowing within network (d) & 0.60 & 0.49 \\
Neighbors like strangers (d) & 0.26 & 0.44 \\
Daily visits (d) & 0.60 & 0.49 \\
Long-term relation (d) & 0.51 & 0.50 \\
\hline
\end{tabular}

Notes: In the dictator game, decision makers received an endowment of 20 L.E. (Egyptian Pound). "Close friends (\#)" is the number of close friends besides the family and "borrowing within network" indicates whether the first two sources of borrowing money are family and close friends. "Neighbors like strangers" indicates the perception of immediate neighbors. "Daily visits" indicates daily interaction with their friend and "long-term relation" indicates whether they know each other for 5 years or longer. 